\title{
The impacts of transportation vehicles on environment: The case of Ho Chi Minh City
}

\author{
Dinh Lo Dinh \\ FPT University, Vietnam.
}

\begin{abstract}
Currently, all people are joining hands to contribute to environmental protection, together heading towards a green and beautiful city. However, environmental pollution in Vietnam is getting more and more serious, especially air pollution. Most of the cause of air pollution is from factory and transport emissions, especially in large cities with densely populated populations such as Hanoi and Ho Chi Minh city, a large amount of emissions big waste released into the environment every day. The polluted air affects the health of the people living in these cities, which is also the main cause of the hot greenhouse effect globally. Despite the calls to protect the environment, such environmental pollution is getting more serious. Therefore, it is very practical to study the air pollution in our country. The paper uses and analyses recent research papers as well as survey results carried out in Ho Chi Minh City to further clarify people's perception of an increasingly serious environmental problem.
\end{abstract}

\section{Introduction}

Air is an extremely important component on the earth, providing the essential conditions to preserve the formation, survival and development of humans and organisms. However, at present, environmental pollution is becoming more and more serious threatening the lives of people and creatures living on earth. Vietnam is currently facing economic development challenges. The country is increasingly developing at the same time also facing environmental problems. In Vietnam, the problem of environmental pollution is a very painful problem in urban areas and industrial zones. Air pollution adversely affects human health, impacts on ecosystems, and climate change such as: greenhouse effect, acid rain, etc. [1]. Two of the big cities like Hanoi and Ho Chi Minh are facing quite serious environmental problems. This is considered a quite difficult task, but we still have not found the most suitable answer. The population density is dense, the amount of vehicles is too large, the awareness of some people is poor, the emissions of factories, etc. were seen as great challenges for a city that was developing very strongly, despite the Covid-19 pandemic. Currently, the rate of air pollution, fine dust and general types of dust in countries have increased to an alarming rate, Ho Chi Minh City one of the largest economic centers in Vietnam is a typical example.

\section{Research content}

\subsection{Air pollution concept}

According to experts, the air environment is a mixture of compounds surrounding the earth to sustain the life of organisms on this planet. Air pollution is a major change in the composition of the air, indicating that the air is polluted, mainly caused by smoke, dust, vapors or foreign gases introduced into the air, causing odors, reducing range. foresight, causing climate change, threatens human health and can also harm other organisms such as animals and food crops, damaging the natural environment. Daily human activities and natural processes can cause air pollution [2].

Dust is a complex mixture of inorganic and organic particles in the form of liquid or solid suspended in the air including sulfates, nitrates, ammonia, sodium chloride, black carbon, mineral dust and water [3]. Collectively known as Particulate Matter - symbol PM. In the air, there is usually PM10 (diameter from 2.5 to 10 $\mu \mathrm{m})$ and PM2.5, however in recent years, our country has appeared PM1.0 (less than $1.0 \mu \mathrm{m}$ ) ultrafine dust and PM0.1 nano dust ( less than $0.1 \mu \mathrm{m}$ ) [4].

\subsection{The cause of air pollution}

There are many causes of environmental pollution in which two main causes of air pollution are natural pollution and human pollution [5].

Air pollution from nature such as forest fires, is one of the main causes of air pollution in Vietnam. According to scientists, the carbon molecules produced by forest fires and the organic matter released into the air have a great effect on the earth's atmosphere, because they block the sun's rays [3]. Besides, storms generate $\mathrm{NO}$ (which is nitrogen and oxygen in the mixture of airfuel), which is the main reason that makes storms 
become the cause of environmental pollution. Along with that, sand storm also carries a lot of fine dust (PM10, PM2.5), making the rate of fine dust increase. Wind is also the cause of dust, gases that travel hundreds of kilometers away, causing the pollution to spread rapidly.

Besides, there is also human impact that makes the air environment more polluted [6]. Human activities such as daily activities, production, construction, transportation, etc. Smoke, dust from factories have a large amount of $\mathrm{CO} 2, \mathrm{CO}, \mathrm{SO} 2, \mathrm{NOx}$, and unburnt organic substances All like soot, dust with extremely high concentrations. In the process of treating, the exhaust gas is not guaranteed to be discharged into the environment, adversely affecting human health. Along with that, the gases from vehicles, especially outdated vehicles. In developing countries, the public transport system has not been strongly developed, making the number of private means of transport dramatically increase, contributing to a very serious impact on the living environment [7].

\subsection{Current situation of air pollution in Ho Chi Minh City}

According to the Vietnam Environmental Monitoring Center, the average concentration of PM2.5 and PM10 fine dust in the air in Ho Chi Minh City is currently exceeding the standards of WHO and has trend at high threshold. The high level of fine dust causes the atmosphere in Ho Chi Minh City to appear "foggy".

Monitoring results of 30 environmental locations in the city show that the air quality has a sudden increase of pollutants such as suspended dust, NO2, SO2, CO, etc.That is why many people go to the street. Wear a mask and get out of the house during rush hour, off work. Affect the daily activities of everyone living here [3].

\section{3.1. Affect the environment}

Air pollution usually occurs when there is a greenhouse gas present in the air, a chemical imbalance or a dense concentration of aerosol particles [8].

Scientists have shown that the main causes of greenhouse effects and climate change are carbon dioxide $(\mathrm{CO} 2)$ and methane $(\mathrm{CH} 4)$. Air pollution causes acid rain, which causes dust and dust to reduce sunlight, affect photosynthesis and plant growth, etc. Sulfur dioxide and nitrogen oxides can cause acid rain. reduces the $\mathrm{pH}$ of the soil. The phenomenon of environmental pollution also makes animals able to invade, compete for habitat and harm local species, thereby reducing biodiversity [6]. $\mathrm{CO} 2$ produced during production and transportation increases the greenhouse effect, global warming, acid rain, destroying existing ecological systems [7]

According to data from Airvisual, which provides information on air quality index (AQI) of cities around the world, Ho Chi Minh City currently has an AQI score of 138. According to the Monitoring Center -
Department of Natural Resources and Environment of Ho Chi Minh City, There is often a layer of "dry blindness" covered here because of the high density of urbanization, many means of transport, many factories with emissions. In addition, the city is receiving more air pollution from industrial cities in Dong Nai and Binh Duong that diffuse in the wind direction (Figure 1).

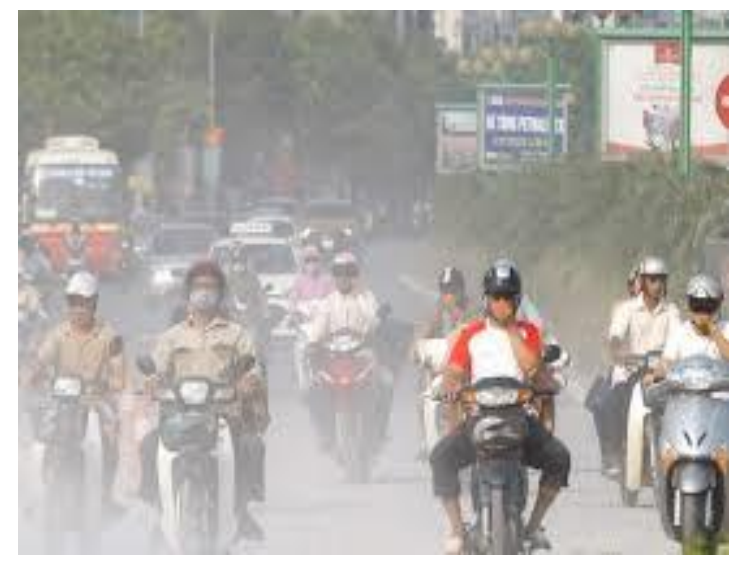

Figure 1. Ho Chi Minh City's pollution status from a distance

\section{3.2 Health effects}

Air pollution is currently considered the world's biggest health and environmental threat. Half of the world's population does not have access to clean technology, 9 out of 10 of these are inhaling polluted air, and up to 7 million people are killed each year from air pollution [10].

The level of air pollution affects people's health very seriously, equivalent to smoking, and much higher than the impact of eating too much salt. Micro-fine dust particles in the air can enter the body's immune system, penetrate deeply into the human circulatory respiratory system, then gradually damage human lungs, heart and brain [4].

Air pollution is both a cause of formation and an exacerbation of a number of diseases, from asthma to cardiovascular disease, lung cancer, ventricular hypertrophy, Alzheimer's and Parkinson's, and psychological complications., autism, retinopathy, etc. Fine and ultrafine dust particles such as PM1 and PM0.1 - one of the main components of polluted air, are classified by the International Cancer Research Agency. cause cancer to humans.

The harmful effects of air pollution on our human health are getting more and more attention by researchers who have demonstrated a link between several serious diseases across age groups. Such as neurological and psychological complications, eye irritation, skin diseases, affecting the development of the fetus, leading to premature birth, low birth weight [9].

According to estimates by the World Health Organization, exposure to air pollution is a risk factor for disease more dangerous than previously thought. Air pollution is the biggest contributor to environmental diseases [4]. 


\subsection{Research method, scope and object}

This research paper was done by the survey method in which online forms were completed thank to the support of 40 respondents who are living in Ho Chi Minh city. The reason the author chose this site is because it is a large city with many environmental problems and it is also convenient to complete the survey.

\subsection{Results and discussions}

Looking at the figure, we can see that according to the opinion of the respondents, the main cause of the air pollution in Ho Chi Minh City is the number of localities. Traffic convenience has increased dramatically in recent years, but the infrastructure is still underdeveloped, making traffic congestion happen every day. There are many respondents agree that poor management and factories also affect the air environment in the city, then low awareness is a next reason (Figure 2).

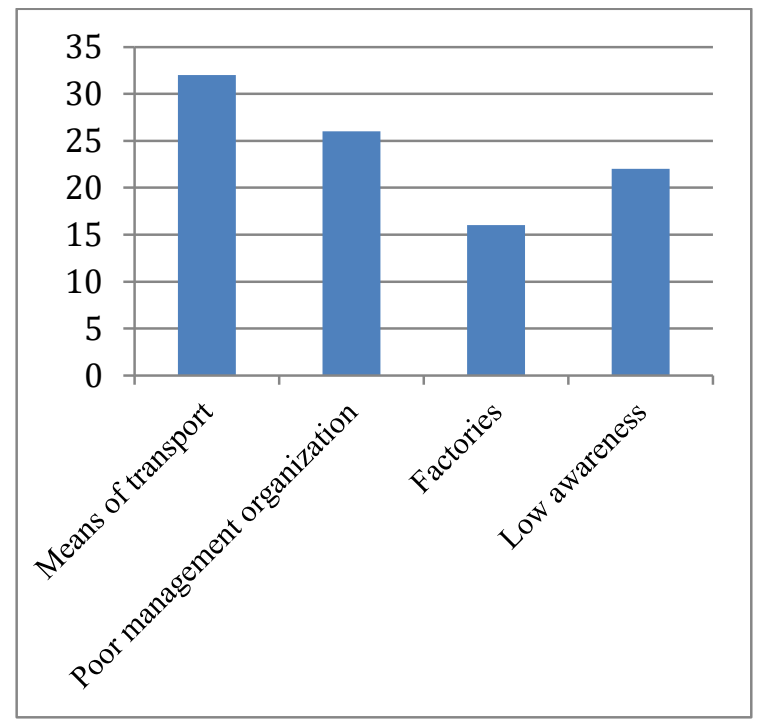

Figure 2. The causes of air pollution in Ho Chi Minh City.

Looking at the figure 2, we can see that $62 \%$ of them realize that the air pollution in Ho Chi Minh City is dangerous alarming, and there is a need to find viable solutions. Only $18 \%$ of people feel that the pollution situation here is normal (Figure 3).

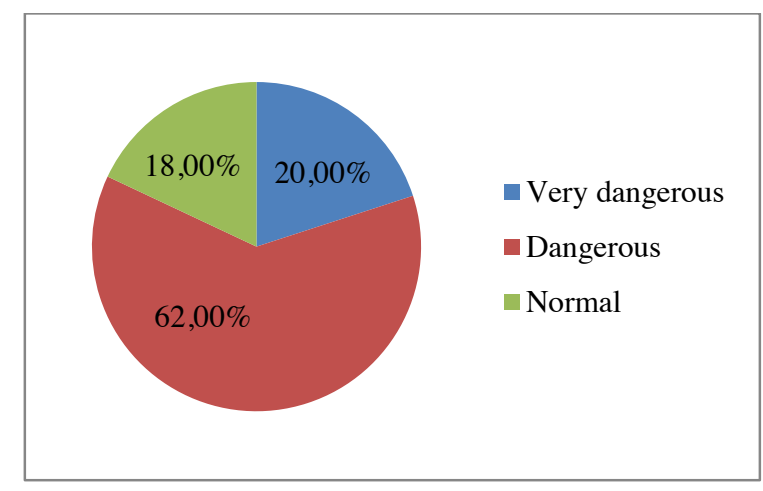

Figure 3. Level of air pollution situation in HCMC.
Through the above research we can see the danger air pollution has brought to our life as well as this living environment. If the density of fine dust pm 1.0 in the air increases to $10 \mu \mathrm{g} / \mathrm{m} 3$, the cancer rate will also increase $22 \%$, and the fine dust density of pm2.5 increases by 10 $\mu \mathrm{g} / \mathrm{m} 3$, the rate of lung cancer will increase. $36 \%$ [5]. With such a high density of fine dust, it greatly affects the health of humans as well as organisms living in this green planet, accelerating the greenhouse effect, global warming, acid rain, etc. Useful measures should be taken to reduce the amount of fine dust discharged into the environment every day, then, we should work together to protect this ecosystem and habitat.

\subsection{Some suggestions}

We need support from the Party and State to promote the construction of public transport works. The current bus system is complicated and out of date, making it difficult for young people to contact, especially those who have never used this type of public transport [5]. The Vietnamese railway system has great potential but is extremely underinvestment, and the State's monopoly over the train system is one of the huge causes of underdevelopment, even so. backward in this type of public transport.

There is also another objective issue, that is because Vietnam is currently in the process of industrialization and modernization, so the number of factories producing a lot, emitting a large amount of emissions during operation. moving. It is advisable to set out regulations on the disposal of production waste to avoid dumping production waste into canals and rivers [7]. Be proactive in planting green trees in the city and architectural works according to international green standards. Encourage malls, supermarkets, markets and people to use paper wrap instead of plastic bags. Encourage people to bring their own bags when shopping. Encouraging people to sort their waste by themselves, making the waste treatment process simpler, saving money to invest in other projects.

It is also impossible not to mention the people's general sense of hygiene in environmental protection. The State needs to organize propaganda for people about simple actions to protect the common living environment such as dumping waste at the right place.

\section{Conclusion}

Along with the process of economic development and the significant increase in population density, the urban areas, residential areas, and industrial zones lack the synchronous and overall planning, making the management and control of the cell contamination from waste sources is more complicated. Transport activities, manufacturing, and construction are the main causes of air pollution. This is an extremely painful problem, not only causing habitat degradation, climate change, serious damage to the economy, but also directly affecting human health and life as well as the development of children in particular and people in general. Solving 
pollution problems is not extremely difficult and it requires us to have long-term strategies, a coordination of all agencies as well as people in working together to protect the living environment.

Acknowledgments. The authors would like to express warm thanks to those who completed the surveys. The author also would like to send thanks to Mr. Le Minh Quang for kind support.

\section{Conflict of interest}

No conflict of interest is noted in the paper.

\section{References}

1. Kean, A. J., Harley, R. A., \& Kendall, G. R. Effects of vehicle speed and engine load on motor vehicle emissions. Environmental science \& technology, 37 17 (2003).

2. Walton, D., Thomas, J. A., \& Dravitzki, V. Commuters' concern for the environment and knowledge of the effects of vehicle emissions. Transportation Research Part D: Transport and Environment, 94 (2004).

3. Danh, N. T. Some benefits of improving urban air quality from the perspective of Ho Chi Minh City people. In E3S Web of Conferences. EDP Sciences. 211 (2020)

4. Le, T. P. L., \& Trinh, T. A. Encouraging public transport use to reduce traffic congestion and air pollutant: A case study of Ho Chi Minh City, Vietnam. Procedia engineering, 142, (2016).

5. Hayashi, Y., Doi, K., Yagishita, M., \& Kuwata, M. Urban Transport Sustainability. European Journal of Transport and Infrastructure Research, 41 (2004).

6. Yedla, S., \& Dhakal, S. Transportation and environment in developing countries. International Journal of Environment and Pollution, 301 (2007).

7. Hoi, H. T., \& Danh, N. T. Greening Houses in the Age of Climate Change. In IOP Conference Series: Earth and Environmental Science. IOP Publishing, 505 1 (2020).

8. Storch, H., \& Schmidt, M. Adaptation Planning Framework to Climate Change for the Urban Environment in Ho Chi Minh City. In EnviroInfo, (2008).

9. Van Than, L. Economic development, urbanization and environmental changes in Ho Chi Minh City, Vietnam: Relations and policies. Urban Population, Development and Environment Dynamics in Developing Countries Conference, (2007).

10. Hoi, H. T. Impacts of Urbanization on the Environment of Ho Chi Minh City. In IOP Conference Series: Earth and Environmental Science, IOP Publishing, 5051 (2020) 